\title{
NOVAS TECNOLOGIAS PARA... NOVAS (?) EXPOGRAFIAS
}

\author{
Maria Júlia Estefânia Chelini ${ }^{\text {* }}$ \\ Museu de Geociências da UnB \\ New technologies for... new (?) \\ expographies
}

\section{RESUMO:}

Os museus têm enfrentado, nos últimos anos, grandes desafios para sobreviver em um mundo onde as fontes de informação e as possibilidades de lazer são inúmeras. $E$ é geralmente por isso, para atrair o público, em especial o público jovem, que os museus têm buscado utilizar novas ferramentas expográficas, que tornem a mostra mais atrativa e motivadora. Dentre estas estratégias merecem destaque as chamadas novas tecnologias. $O$ presente texto tem por objetivo discutir, através de exemplos positivos e negativos, o uso das tecnologias como ferramenta expográfica, alertando para o uso tentador, e muitas vezes irrefletido, que se faz destas novidades.

\section{PALAVRAS-CHAVE:}

Museu, Expografia, Novas tecnologias, Interação, Público visitante.

\begin{abstract}
:
Museums have faced, in recent years, challenges to survive in a word with countless information sources and recreation possibilities. As a consequence, in order to attract the public, specially young audience, museums are trying new expographic tools that make their exhibition more appealing and motivating. New technologies are one of these tools. The present text will discuss, giving positive and negative examples, the use of technologies as expographic tools, drawing attention to its tempting and sometimes thoughtless use.
\end{abstract}

\section{KEY-WORDS:}

Museum, Expography, New technologies, Interaction, Visitors.

\footnotetext{
Bióloga. Desenvolveu doutorado, pela Universidade de São Paulo, analisando a divulgação científica através de exposições em Museus de Ciências. Concomitantemente, participou de projetos de desenvolvimento de materiais para o Ensino Formal e Não-Formal na Faculdade de Educação e Instituto de Biociências USP.Atuou como Analista de Comunicação no Museu Paulista da USP (Museu do Ipiranga), onde ocupou cargo de Diretora Técnica da Divisão de Difusão Cultural.Atualmente, desenvolve ações como Extensionista Colaboradora junto ao Museu de Geociências da UnB, ocupando Coordenação responsável pelos projetos de extensão dentre os quais a nova exposição de longa duração; e-mail: jchelini@unb.br
} 
Afirmações como "o mundo hoje é tecnológico" e "não se pode mais viver sem tecnologia" são muito usuais nos dias atuais. $O$ termo tecnologia tem sido associado à modernidade, à inovação e agrega um valor positivo às coisas em geral, quaisquer que sejam essas coisas... Mas este texto não tem por objetivo fazer uma apologia ao tradicional e renegar as ditas "novas tecnologias". Ao contrário, o objetivo dos apontamentos aqui apresentados é discutir o uso das tecnologias como ferramenta expográfica, alertando para o uso tentador, e muitas vezes irrefletido, que se faz destas novidades tecnológicas.

Antes de ir mais adiante, alguns pontos precisam ser esclarecidos: I. O que é tecnologia? e 2. O que são as chamadas "novas tecnologias"?

O termo "tecnologia" vem da associação dos termos gregos "tekne" (arte, técnica ou ofício) e "logos" (conjunto de saberes). Assim, tecnologia pode ser definida como o conjunto de instrumentos, métodos e técnicas que permitem o aproveitamento prático do conhecimento científico. Ao construirmos uma máquina do tempo, pregarmos um botão, pintarmos uma parede ou cortarmos o cabelo, fazemos uso de tecnologia. Como se vê, uma tecnologia não é necessariamente uma inovação.

A palavra tem sido utilizada como sinônimo de "tecnologias da informação", que são aquelas que permitem a criação, administração e difusão da informação através de dispositivos e equipamentos de acesso, operação e armazenamento de dados. A tecnologia da informação inclui, por exemplo, tudo o que está relacionado com os computadores. E nesse sentido as "novas tecnologias" poderiam ser definidas como as novidades relacionadas ao campo da tecnologia da informação: novos games, novos aparelhos celulares, novo tipo de televisão etc.

Do ponto de vista museográfico, as "novas tecnologias"2 estão muitas vezes associadas a possibilidades de criação de interação visitante-exposição. E a interação é tida, em especial nos museus de ciência, como elemento fundamental para efetividade da comunicação da exposição.

Ao analisar os visitantes espontâneos dos museus, Screven (1993, p. I I) indica que a maioria destes tem uma forte orientação visual/sensorial, ou seja, seu interesse se volta à exploração visual do ambiente museal, principalmente dos objetos e outros elementos de encenação. $O$ autor definiu ainda que, em uma escala de atratividade, os elementos de uma exposição que despertariam prioritariamente o interesse dos visitantes são os organismos vivos, seguidos dos objetos que se movem ou que convidam o visitante a utilizar seus sentidos (tocar, manipular), e as novidades (elementos recentes, únicos ou que formam conjuntos inusitados). Nesta escala, os elementos não prioritários compreenderiam os painéis, murais passivos bidimensionais, e os textos tradicionais (SCREVEN, I 993, p. II).

O fato é que, atualmente, ao circular por uma exposição de um museu, o visitante não busca mais uma experiência puramente contemplativa. Ele realmente espera, como mencionado por Hughes (2010, p. I54), encontrar um botão a apertar, um controle a ser utilizado, alguma forma de participação ou interação com a exposição. $\mathrm{E}$ a interação que foi, por muitos e muitos anos, quase que uma exclusividade dos museus de ciências é, atualmente, considerada como importante ferramenta de comunicação para qualquer tipologia de exposição.

I Neste texto utilizaremos as palavras "tecnologia" e "tecnológico" para nos referir às "novas tecnologias". 
As exposições são, como já afirmava Cury (2005, p. 35), a principal ou mais específica forma de comunicação de um museu. E, para Martins (2005, p. 10), o objetivo de toda exposição é o de criar as condições para que o público tenha "uma experiência única" de apreciação. Neste sentido, Scheiner (2003) indica que entender a exposição como espaço relacional significa, antes de tudo, buscar percebê-la como instância de impregnação dos sentidos. Mas como provocar esta impregnação?

Já há mais de 30 anos, Alexander (1979) apontava favoravelmente a exploração das diferentes percepções sensoriais, e não apenas da visão em uma exposição. Isto porque estímulos sensoriais podem proporcionar reações emocionais, e estas, ao trabalharem em conjunto com o racional, levariam a uma melhor compreensão da exposição. Assim, a ampliação do leque de sentidos estimulados poderia ser um catalisador de todo o processo. Wagensberg (2000, p. I6) também acredita que as exposições devem estimular os visitantes, e para ele estes estímulos se dão através da interatividade.

Colinvaux (2005, p. 8I), que buscou analisar, a partir da perspectiva do visitante, a experiência vivida no espaço-tempo de um museu por aqueles que o visitam, indica que a interatividade parece estar no cerne da experiência museal. Ainda segundo a autora, a interatividade nos museus pode ocorrer entre sujeitos, entre sujeitos e objetos, e também entre sujeitos e contextos, onde o museu é contexto para a ação do sujeito.

Em relação aos museus, McLean (1993, p. 92) destaca que o termo "interativo" tem sido utilizado como sinônimo de "participativo" ou "manipulativo" o que pode gerar confusões. A autora lembra que nem toda manipulação é uma interação e que a interação acontece quando o visitante age sobre a exposição e esta faz algo que age sobre o visitante. Assim, o termo "participativo" define a relação do visitante com a exposição enquanto o termo "interativo" enfatiza a capacidade da exposição de responder a estímulos do visitante (MCLEAN, I 993, p. 93).

O termo "interação" também costuma nos remeter a algum grau de atividade física, mas Asensio e Pol (1996, p. 18) expõem que, a seu ver, a interatividade deveria ter uma base cognitiva, centrada na análise do processo mental e no produto resultante. Os autores citam como exemplo que a mente de um especialista, frente à obra de Frei Angélico, está desenvolvendo uma interatividade de alto nível, embora seu corpo permaneça estático.

Neste sentido,Wagensberg (2000, p. I6) defende que uma exposição pode apresentar três níveis de interatividade: hands on (manual), minds on (mental) e heart on (cultural). No primeiro nível, a interatividade manual (hands on), classificada pelo autor como conveniente, o visitante manipula modelos, objetos ou montagens que the permitam entender o funcionamento e o desenrolar de processos e fenômenos. É a ideia de que o visitante experimenta o método científico, o visitante "é" o cientista.

Por sua vez, a interatividade cultural (heart on), definida como recomendável, pode ser promovida quando uma exposição tenta priorizar as identidades presentes no entorno do museu, promovendo a identificação do visitante da comunidade local com o acervo e um despertar para uma nova cultura, quando o visitante é de outras localidades.

Mas é a interatividade mental (minds on) que deve levar a uma compreensão científica, permitindo distinguir o essencial do acessório, ver o que há 
de comum entre o que é aparentemente distinto, estabelecer relações entre o que se vê no museu e no cotidiano. E é por isso que Wagensberg (2000, p. 16) a classifica de imprescindível.

Embora os diferentes níveis de interatividade estejam cada vez mais presentes nas exposições, os museus têm enfrentado, nos últimos anos, grandes desafios para sobreviver em um mundo onde as fontes de informação e as possibilidades de lazer são inúmeras. Uma exposição tem, nos dias de hoje, de competir com muitas outras opções que se apresentam ao potencial visitante. E é geralmente por isso, para atrair o público, em especial o público jovem, que os museus têm buscado fazer uso de novas ferramentas expográficas, que tornem a mostra mais atrativa e motivadora. Dentre estas estratégias merecem destaque as chamadas novas tecnologias.

Sartin (2010, p. 262) comenta que a tecnologia, nos dias correntes, facilita muito a comunicação com o público em geral, especialmente os segmentos jovens. $O$ que não significa, no entanto, que a interatividade promovida por aparatos não computadorizados não seja, como mencionado por Hughes (2010, p. 154), efetiva. E, embora a interatividade hoje envolva, em muitos casos, o uso de computadores, Sartin (2010, p. 262) ressalta que tal tecnologia destaca os conteúdos apresentados pelo museu quando utilizada com responsabilidade e pertinência, fugindo dos eventuais recursos fáceis de pirotecnia expositiva.

Em trabalho de 2003, Scheiner (2003, p. 2) já comentava:

Quero dizer que o controle excessivo e absoluto da técnica pode ajudar a criar magníficos espetáculos visuais ou multimídia, que mobilizem os sentidos do visitante no plano cognitivo (curiosidade) ou motor (movimento), mas que dificilmente poderão gerar instâncias de verdadeira mobilização afetiva. Pois é no plano afetivo que se elabora a comunicação: é no afeto que a mente e o corpo se mobilizam em conjunto, abrindo os espaços do mental para novos saberes, novas visões de mundo, novas experiências, novas possibilidades de percepção.

O mundo está mudado, ninguém duvida disso. As ferramentas à disposição para construção da expografia são muitas e a evolução tecnológica nos mais diferentes campos permitem, a cada dia, fazer uso de novas mídias. A inserção das tecnologias no espaço expositivo já não é apenas conveniente, mas inevitável. Oliveira (20I2, p. 185) destaca, neste sentido, que "mais que lamentar as trocas nas mídias, os museólogos, técnicos e profissionais de museus devem examinar de que maneira isso pode afetar na comunicação que o museu proporciona". Já há muitos anos discute-se, mesmo para as mais tradicionais exposições, a adequação de determinadas mídias ou suportes a determinados propósitos. Agora a mesma questão deve ser aplicada às novas tecnologias: que mídias servem a que mensagem?

Neste sentido, é importante também a reflexão sobre o impacto de determinadas tecnologias: não seriam elas, por vezes, mais atraentes por si só que a mensagem que estão encarregadas de passar? Não estariam ofuscando, por seu apelo inovador, o acervo que se propõem a destacar? Não é raro ouvir relatos acerca do deslumbre de visitantes frente a novas tecnologias utilizadas em certas exposições. As conversas destes se portam muitas vezes prioritariamente sobre o funcionamento tecnológico do aparato; o acervo ou conceito discutido pela exposição ficando em terceiro ou quarto plano... Se 
as exposições são um espaço de vivência, que vivências estão sendo proporcionadas com estes aparatos?

Múltiplos são os fatores (históricos, tecnológicos, culturais e até sociológicos) que poderiam entrar nesta discussão, a exemplo da possibilidade de inclusão tecnológica proporcionada por tais equipamentos. Mas, do ponto de vista puramente expográfico e comunicativo, a busca, fica claro, deve ser por um equilíbrio em que as novas tecnologias realmente auxiliem o museu em sua comunicação, ou seja, que as novas tecnologias sirvam ao museu, e não o contrário.

Assim, no processo de montagem de uma nova exposição devem ser levadas em conta questões como: o que esta mídia ou tecnologia está possibilitando expograficamente? Que interação ela está propondo? Que experiência poderá proporcionar? Ela permite trazer para o museu algo que não seria possível mostrar de outra forma? Ou apenas se repetirá com esta ferramenta um modelo tradicional?

As tecnologias têm sido associadas às exposições essencialmente de duas formas: para aporte de informações complementares ou como parte integrante da exposição.Valinho e Franco (2005, p. I626) identificam quatro formas de utilização das novas tecnologias que podem favorecer o envolvimento dos visitantes com o espaço museológico que denominam de: Reconstrução do passado; Substituição do real ausente; Contadora de Histórias e Guia do espaço museológico. A primeira, Reconstrução do passado, permitiria a contextualização, virtualmente, de objetos reais numa simulação do seu espaço e tempo originais. Como exemplo mencionam o uso de tecnologia geradora de Realidade Aumentada (RA) 3 para exemplificar o uso de um ornamento corporal original.Valinho e Franco (2005, p. 1626) destacam, no entanto, que a utilização de dispositivos de RA não deveria substituir a peça original ou estar continuadamente sobreposto à mesma e que uma análise detalhada do contexto de uso e da interação proposta deve ser feita antes de optar-se por esta estratégia.

Embora faça uso de tecnologias semelhantes à da tipologia anterior, os autores definiram separadamente esta segunda categoria, Substituição do real ausente, em virtude de seu objetivo. Neste caso, a tecnologia torna-se o objeto exposto ao substituir, de alguma forma, objetos reais. Os autores não discutem, mas entende-se que esta opção pela substituição pode se dar por variados motivos, como a não existência no acervo de determinada peça relevante para o contexto da exposição, ou ainda por motivos vinculados à conservação (a extrema fragilidade de determinada peça poderia inviabilizar uma interação que a RA pode proporcionar).

Muitas exposições contam histórias, histórias de objetos, de pessoas, de eventos, de processos. Se já tradicionalmente se faz uso de diversas estratégias midiáticas para contar estas histórias, a tecnologia só vem aumentar estas possibilidades. Daí a definição, pelos autores (VALINHO; FRANCO, 2005, p. 1627), da terceira forma de utilização da tecnologia, a Contadora de Histórias que, ao criar instalações interativas, recorrem a sistemas de som direcional e detecção de movimento ou proximidade para comunicar com os visitantes.

2 Seguiremos neste texto a definição de Valinho e Franco (2005, p. 1626) que entende a realidade aumentada como "todo o tipo de sistema tecnológico que permite a adição de informação à realidade; ou seja, integra elementos virtuais no espaço real, em tempo real". 
Para os autores, este tipo de sistema implica em uma identificação cuidadosa do público-alvo e consequente adequação ao tipo de conteúdo veiculado.

Enquanto as duas primeiras categorias referem-se essencialmente ao uso da tecnologia como parte integrante da exposição, a terceira pode ser utilizada de ambas as formas, parte integrante ou ponto de informação complementar. É o caso, por exemplo, dos totens informativos que disponibilizam informações na forma de hipertextos ou vídeos.

Já a quarta categoria definida pelos autores remete ao uso de tecnologia predominantemente para aporte de informações complementares, é - Guia do espaço museológico. Nesta categoria, segundo Valinho e Franco (2005, p. 1627), enquadram-se os dispositivos de audioguia que proporcionam aos seus utilizadores uma visita autônoma pelo espaço. Aos já tradicionais equipamentos de audioguia somam-se agora equipamentos que, além de som, oferecem ao visitante possibilidade de leitura e/ou visualização de imagens e vídeos. Aliados a sistemas de base de dados, estes equipamentos permitem a seus usuários, por aproximação do objeto, acessar informações adicionais sobre determinadas peças em exposição.

A partir destas diferentes formas de utilização das novas tecnologias definidas por Valinho e Franco (2005, p. 1626), vamos analisar algumas das principais questões apontadas em pesquisas publicadas de avaliação de aparatos interativos utilizados em exposição e que façam uso de novas tecnologias. Aos tratarmos de dispositivos como totens e audioguias, uma questão que tem sido levantada é a do isolamento dos visitantes que fazem uso destes equipamentos. Já é de conhecimento geral que as interações sociais no espaço expositivo são de grande valia para a riqueza da experiência do visitante, incluindo o processo de aprendizagem que esta pode acarretar. Vom Lehn, Heath e Hindmarsh (2010, p. 5), destacam que ao se planejar uma exposição, não se pode deixar de levar em conta que as pessoas, geralmente, analisam e compreendem uma exposição através da interação social, não só dentro do grupo que as acompanha, mas também em função de outros visitantes que porventura estejam no mesmo espaço. Os autores (VOM LEHN; HEATH; HINDMARSH, 20I0, p. 2) comentam que, no entanto, em muitos museus, não só os quiosques de informação, mas até alguns outros tipos de aparatos interativos, fazem uso de interfaces reduzidas, como os monitores de computadores para uso individual, o que dificulta a exploração coletiva do equipamento. Alguns museus, como o Berlin Museum für Naturkunde (HORNECKER, 2008), têm tentado contornar este problema com o uso de mesas interativas. Essas superfícies, de maior dimensão, geralmente permitem a exploração conjunta do dispositivo, por diversos visitantes simultaneamente, evitando assim as filas que se formam por vezes em quiosques individuais. Estes aparatos, segundo Hornecker (2008, p. I26) também permitem que alguns visitantes possam apenas observar a interação executada por outros, usufruindo assim dos resultados obtidos ou textos gerados. No entanto, a avaliação conduzida revelou que embora cerca de metade dos visitantes interaja com a mesa e mais $25 \%$ observe as interações, só uma pequena parcela do público (cerca de 17\%) despende mais tempo no aparato (mais de apenas um ou dois toques) (HORNECKER, 2008, p. I26).

A sensação de isolamento do visitante também pode ser observada em situações de uso de audioguias. A observação de alguns grupos de visitantes mostrou a vom Lehn, Heath e Hindmarsh (2010, p. 3) tentativas, por parte de 
visitantes em grupo, de coordenar a exploração da exposição, seja por divisão de tarefas (um ouve e relata aos outros que observam o objeto e comentam o relato) ou sincronização dos dispositivos (diversos fones para I dispositivo ou disparo da informação simultaneamente nos diferentes dispositivos do grupo). Apesar destas tentativas, o que se tem, em geral, é que, para além de tornar a visita à exposição uma experiência individual, estes dispositivos podem torná-la uma experiência solitária.

Ainda com relação à questão das informações complementares, é interessante a pesquisa, realizada no United States Holocaust Memorial Museum e apresentada Swiader (2005), que avaliou a exposição permanente do museu e buscou analisar como a tecnologia poderia ser utilizada na exposição visando estender a experiência do visitante para além muros. $\mathrm{Na}$ avaliação, ao serem perguntados sobre o desejo de ter acesso a mais informações, $31 \%$ dos visitantes responderam que gostariam de receber mais informações durante sua visita enquanto $61 \%$ manifestaram-se a favor da possibilidade de ter acesso a mais informação, mas em outro momento (SWIADER, 2005, p. 3).Assim, o autor defende que os museus deveriam fazer uso das tecnologias não para fornecer cada vez mais informações dentro de seu espaço físico, mas para gerar novos vínculos com o público visitante, em momento posterior à visita. Uma estratégia que apresenta é o uso pelo visitante de um cartão que permitiria a coleta por radio frequência, ao longo da visita, de informações sobre a mostra e/ou pontos específicos desta. Posteriormente, o visitante poderia, pela internet, ter acesso a uma página pessoal onde as informações coletadas no museu apareceriam de maneira organizada, por exemplo, em função das linhas temáticas da instituição. A partir deste ponto, diversas estratégias poderiam ainda ser desenvolvidas como a criação de grupos online de visitantes com interesse em comum (SWIADER, 2005, p. 3). O museu poderia, inclusive, a partir desta tecnologia, mapear os pontos da exposição que despertam maior interesse. Neste caso, a tecnologia não estaria a serviço do museu apenas no momento da visita, mas permitiria reforçar os laços do museu com o visitante fora de seus muros.

Este tipo de dispositivo foi avaliado por Hornecker e Stifter (2006a) em exposição de longa duração sobre a história da mídia apresentada pelo Austrian Technical Museum Vienna. $O$ visitante podia adquirir um cartão de memória e coletar dados disponíveis (informações complementares na forma de fotos, vídeos ou textos) ou gerados pelos próprios visitantes (vídeos, fotos, resultados de jogos) durante o seu percurso. Posteriormente, via internet, o visitante podia acessar estes conteúdos, além de editar seu perfil, receber dicas sobre novos pontos da mesma exposição a visitar que sejam complementares aos temas que registrou, trocar mensagens com outros usuários do cartão. Um ponto interessante que a avaliação revelou foi que visitantes com cartão tendem a ficar mais tempo no espaço expositivo do que os que não o possuem. Também identificou-se o uso do cartão em múltiplas visitas por cerca de $14 \%$ dos visitantes, o que reforçaria a ideia de potencial gerador de vínculo visitante-museu. Por outro lado, apenas cerca de $41 \%$ dos usuários do cartão realmente acessaram seu conteúdo exclusivo online, mas, destes, 2/3 acessaram mais de uma vez. Hornecker e Stifter (2006a, p. 103) também destacaram o uso do cartão como souvenir, uma vez que este permitia o registro de fotografias e vídeos do próprio visitante em alguns pontos da exposição 
(25\% dos dados registrados, em oposição a $8 \%$ com informações complementares). Embora diversos problemas no uso propriamente dito tenham sido detectados, Hornecker e Stifter (2006a, p. 104) concluem que o conceito do cartão de memória é aprovado pelos visitantes em geral que, inclusive, o entendem como uma ferramenta de uso compartilhado pelo grupo, aumentando as possibilidades de interação social.

Como já mencionado, além do Guia do espaço museológico, a forma Contadora de Histórias definida porValinho e Franco (2005, p. I627) também pode ser empregada como estratégia de aporte de informações complementares. No entanto pode ainda apresentar-se como parte integral da exposição, caso em que tende a fazer uso não só de hipertextos, mas também de áudios e vídeos. Estes três formatos, como já apontado por Chelini e Lopes (2010, p. 373), são considerados suportes alternativos aos tradicionais pôsteres e etiquetas para apresentação de informações textuais.

É crítica comum às exposições, em especial às de cunho científico, a grande quantidade e extensão dos textos impressos. Quanto às outras modalidades textuais (hipertextos, vídeos e áudios), se sua quantidade ou extensão são criticadas, essa critica não é tão veemente quanto aquela feita aos textos tradicionais. Existem na literatura numerosos trabalhos discutindo e recomendando tamanhos máximos ideais para um pôster tradicional; não se discutem tanto os hipertextos. Algumas exposições atuais eliminaram totalmente de seus espaços os textos impressos, o que não significa que o texto não continue muito presente na exposição em terminais de hipertextos e audiovisuais. Não seria a leitura em terminais de hipertextos tão cansativa quanto em textos impressos? Por se tratar de uma ferramenta diferente, mais "atual”, muito conteúdo tem sido gerado para esse suporte. Mas onde estará agora a preocupação com textos longos? É fundamental, sem dúvida, que os museus se atualizem e façam uso de novas tecnologias. No entanto, é também fundamental que seus limites sejam mapeados para que erros, já tão discutidos no passado, não sejam reproduzidos sob nova roupagem.

A tecnologia Contadora de história também pode ser considerada aquela utilizada em múltiplos aparatos interativos que demonstram um fenômeno, explicam um processo ou a forma de funcionamento de algum equipamento ou tecnologia, relatam a origem de alguma espécie, obra, lugar ou cultura. $O$ design de aparatos interativos não deve ser considerado de fácil execução, em especial se envolve o uso de recursos computadorizados.

A literatura tem destacado a importância de que os aparatos interativos sejam simples, imediatos e intuitivos, ou seja, o visitante deve conseguir, rapidamente, ter uma ideia de com que está interagindo, o que aquele dispositivo faz e como funciona (HUGHES, 20 I0, p. I54;VALINHO; FRANCO, 2005, p. 1633). Isso por que visitantes têm um tempo e paciência limitados para explorar o museu. Neste sentido, Hornecker e Stifter (2006b, p. 138), destacam em sua pesquisa que em um dos dispositivos apresentados na exposição do Austrian Technical Museum Vienna que avaliaram, os visitantes demoravam pelo menos dois minutos para entender seu funcionamento. $O$ que resultava é que a maioria desistia rapidamente de se engajar naquela interação. $O$ mesmo ocorreu no Berlin Museum für Naturkunde, onde os visitantes apontaram uma mesa interativa em avaliação como um aparato tecnológico de efeito ou um brinquedo para crianças confuso; divertido talvez, mas cujos objetivos não 
eram muito claros (HORNECKER, 2008, p. I27). Assim, Hornecker e Stifter (2006b, p. 139) lembram que em um espaço como uma exposição, dividido por diversos dispositivos, em que o tempo é restrito e que muito depende do engajamento voluntário do visitante, a rapidez de percepção do aparato e da recepção de uma resposta são vitais para garantia da interação: os 10 primeiros segundos são fundamentais. Hughes (2010, p. 155) acrescenta ainda que, se a proposta da interatividade se estende para além deste primeiro contato, novos desafios e respostas rápidas deveriam ser propostos aos visitantes para mantê-los estimulados.

Neste sentido, Hughes (2010. p. I56) lembra ainda que todas as interatividades baseiam-se em ideias preconcebidas de como as coisas são controladas e como se interage com elas. Assim, a introdução de uma nova interface na exposição deveria despertar no visitante memórias de outras experiências de forma que rapidamente ele entenda como interagir com o dispositivo. No caso de interatividades que envolvem sistemas computadorizados, são inúmeras as possibilidades de interação que podem ser propostas o que torna seu design ainda mais desafiador. Já as interatividades físicas tendem a ser, em geral, mais intuitivas uma vez que uma alavanca sempre será uma alavanca, um botão será um botão, e assim por diante. Aqui, Hornecker e Stifter (2006b, p. 139) apontam que, no caso do museu de Viena, os dispositivos interativos de maior sucesso, com qualquer parcela, tanto em idade quanto interesse, do público visitante, foram aqueles que mesclavam objetos reais com sistemas computadorizados. Um exemplo citado pelos autores era um dispositivo chamado Ábaco, em que um ábaco real podia ser manipulado pelos visitantes e cujos resultados das contas eram apresentados em um monitor que, por sua vez, oferecia novos desafios. Segundo os autores, os visitantes mais novos eram desta forma atraídos pelo aspecto "moderno" do aparato e levados a manipular objetos históricos enquanto os mais velhos, mais resistentes aos aparatos computadorizados quando isolados, viam-se atraídos pelo dispositivo por apresentar um objeto real de interesse histórico e eram levados a interagir com um dispositivo eletrônico (HORNECKER; STIFTER, 2006b, p. I39).

Outro aspecto levantado por Screven (1993, p. I2) é que, se a possibilidade de interagir pode, como já mencionado, suscitar a atenção do visitante, ela pode também distrair o visitante, fazendo-o inclusive perder a linha de raciocínio da exposição, se não for cuidadosamente integrada aos objetivos educativos. $O$ autor chama a atenção para o fato de que, muitas vezes, o visitante pode explorar um elemento museográfico interativo sem, no entanto, refletir sobre o que está fazendo. Cita, por exemplo, que divertimento e participação, muitas vezes observados nas exposições de divulgação científica, não significam que a educação científica esteja realmente acontecendo, podendo ser simples reflexo da excitação provocada pela liberdade de exploração, e defende que uma boa opção seria subordinar elementos divertidos à atenção e ao aprendizado, uma vez que, para ele, no museu, a diversão deve ser um meio para se atingir um objetivo, o aprendizado, por exemplo, e não o objetivo em si (SCREVEN, 1993, p. I2).

Já no que tange a sua aparência,Valinho e Franco (2005, p. I633) comentam que, para além de ser bem desenhado, de forma a garantir uma imediata comunicação com o visitante, o sistema deveria ser suficientemente invisível para garantir a sua integração no espaço expositivo. 
Em diversos museus é possível observar o uso de tecnologias de forma a criar uma ambientação para imersão do visitante no assunto tratado, o que remete à Reconstrução do passado, como definida por Valinho e Franco (2005, p. I626). Hughes (20 I0, p. I63) destaca que submergir o visitante com imagens, sons, cheiros e texturas, de certa forma isola-o e força sua atenção, obrigando-o a se engajar diretamente com a exposição e seus temas. Por outro lado Scheiner (2003) adverte que "o excesso de impacto pode 'anestesiar' os sentidos, projetando o indivíduo para fora de si mesmo e diminuindo o potencial de percepção".

Em 1989,Arpin já advertia quanto ao uso tentador do que ele chamou de uma gadget museology, ou seja, exposições que utilizam um excesso de dispositivos mecânicos ou tecnológicos e assim se tornam verdadeiro mostruário de efeitos especiais. A seu ver, todas essas ferramentas ou todas essas formas de apresentação favorecem a contextualização, cativam o visitante e criam uma atmosfera agradável, o que, sem dúvida, faz parte da mensagem do museu, mas que não poderiam ser "a mensagem" (ARPIN, 1989, p. 67).

Por outro lado, a Substituição do real ausente (VALINHO; FRANCO, 2005, p. 1626) não busca criar ambientes que impactem o visitante, mas exploram a tecnologia para apresentar algo que provavelmente seria inatingível ao público visitante de outra forma. $O$ objeto real tem ferrenhos defensores como Wagensberg $(2000,2005)$, mas não há dúvidas de que reflexões se impõem acerca da coexistência e até sobrevivência destes objetos tradicionais frente às novas tecnologias. Para Wagensberg (2000, p. 16) textos, imagens, jogos, simulações, cenografias e modelos, devem ser considerados acessórios e complementares, mas a exposição deve basear-se no real.Wagensberg (2005, p. 310) salienta ainda que a ciência procura entender a realidade e que esta é composta por objetos e fenômenos; sendo os últimos entendidos, aqui, como as mudanças experimentadas por objetos. Isto significa que a realidade, seja na forma de objeto ou fenômeno, é um fator insubstituível nos museus de ciência, um "must-have”. Wagensberg (2005, p. 3 I0) vai além, considerando que o museu é realidade concentrada.

Wagensberg (2005, p. 314) complementa ainda que as exposições sem uma parcela mínima de realidade são reduzidas a livros que se leem de pé ou a cinemas multiplex em uma só sala.Acrescenta que uma exposição pode ser considerada fraca se pode ser substituída, com vantagem e sem sair de casa, por um bom livro, um bom vídeo, uma boa conexão de internet: um visitante pode ir vê-la, mas, provavelmente, preferirá não ir. Neste sentido, Alexander comentava, já em 1979, que, neste último caso, seria melhor se a equipe do museu investisse suas energias na produção de publicações ou de filmes que - público pudesse desfrutar confortavelmente instalado em uma poltrona, em casa ou em um auditório (ALEXANDER, 1979, p. I78).

Além dos apontamentos já feitos, Hughes (2010, p. 157) destaca ainda um aspecto a ser levado em conta quando um museu decide inserir dispositivos tecnológicos, em especial os interativos, em suas exposições: o custo e o tempo de produção. Aparatos interativos envolvendo interfaces computadorizadas precisam de tempo para serem desenvolvidos e testados até seu funcionamento perfeito, principalmente se levarmos em conta que cada um deveria ser pensado especialmente para a exposição em que estará inserida. Neste sentido, é realmente importante que os dispositivos sejam pensados 
para cada exposição, e não encaixados na exposição por que experimentados e apreciados em outros espaços. $O$ sucesso de determinadas soluções técnicas, adequadas a algumas propostas expositivas, ao serem transferidas a outros espaços podem parecer apenas uma colagem mal feita.

Com relação aos custos, devemos levar em conta não apenas aqueles referentes à produção do dispositivo, mas ainda aqueles de manutenção. Aparatos interativos, por serem amplamente manipulados, tendem a sofrer frequentes danos, sendo os aparatos computadorizados, em geral, mais frágeis que os de pura interação física. Para garantir ao visitante uma experiência completa, é fundamental que estes danos sejam rapidamente percebidos e revertidos. Esse processo não é isento de custos e, certamente, quanto mais tecnológica uma exposição, maior terá de ser a verba destinada a sua manutenção.

Os pontos levantados não têm por objetivo desincentivar o uso das novas tecnologias. Assim como qualquer outra ferramenta midiática, a expografia deve se modernizar. Podemos, e talvez até tenhamos que, fazer uso das novas tecnologias hoje à nossa disposição.

O mundo pede, exige até, novidades e muitos museus têm tentado atender a esta demanda, buscando criar atrações inovadoras e, por que não dizer, espetaculares. Mas quais são as propostas verdadeiramente inovadoras? Quais são as propostas que fazem diferença, provocam mudanças? E, principalmente, quais propostas são mera repetição, talvez em nova roupagem, mas ainda assim repetições? Seria a transposição de tradicionais estratégias para estas novas ferramentas suficiente para torná-las modernas e, quiçá, compreensíveis? Transferir antigas estratégias (muitas vezes consideradas ruins) para uma nova tecnologia não é sinônimo de inovação e é certo que o público não se deixará enganar por muito tempo. Ao discutir a inserção de tecnologias na exposição, Scheiner (20I2, p. 3) destaca que passamos por um "movimento difícil, dada a enorme sedução das novas tecnologias, que nos projetam num vórtice de sentidos como jamais, antes, experimentamos. E porque somos presas fáceis desta sedução, nem sempre desejaremos ir além da esfera mais rasa da mera sensação[...]”.

As estratégias tradicionais e as novas tecnologias são apenas ferramentas, o importante é, como já apontado por Hughes (20I0, p. 154), a experiência vivenciada pelo visitante independentemente da tecnologia empregada.

\section{Referências}

ALEXANDER, Edward P. Museums in motion: an introduction to the history and functions of museums. Tennessee:American Association for State and Local History, 1979.

ARPIN, Roland. Pour les années quatre-vingt-dix, un marriage à trois; museologie, communication et pédagogie. In: SCHIELE, Bernard (Ed.). Faire voir, faire savoir: la museologie scientifique au présent. Canada: Musée des Civilisations, 1989.

ASENSIO, Mikel; POL, Elena. ¿Sieguen siendo los dioramas uma alternativa efectiva de montaje? Revista de Museologia, Madrid, n. 8, p. I I-20, jul. 1996.

CHELINI, M. J. E.; LOPES, S. G. B. C. Textos em museus de ciência: discurso científico, didático ou de divulgação?. In: BENCHETRIT, S. F.; BEZERRA, R. Z.; 
MAGALHÃES,A.M. (Org.). Museus e comunicação: exposições como objeto de estudo. I. ed. Rio de Janeiro: Museu Histórico Nacional, 20 I0. v. I, p. 369-392.

COLINVAUX, Dominique. Museus de ciências e psicologia: interatividade, experimentação e contexto. História, Ciências, Saúde-Manguinhos, v. 12, suplemento, p. 79-9I, 2005.

Cury, Marília Xavier. Exposição: concepção, montagem e avaliação. São Paulo: Annablume, 2005.

Hornecker, Eva. "I don't understand it either, but it is cool": visitor interactions with a multi-touch table in a museum. In: IEEE INTERNATIONAL WORKSHOP ON HORIZONTAL INTERACTIVE HUMAN COMPUTER SYSTEMS, TABLETOP, 3., 2008. Proceedings... Amsterdam: IEEE, 2008. p. I 2 I 128. Disponível em: <http://www.ehornecker.de/Papers/BerlinMuseumTabletop08.pdf>. Acesso em: 20 jun. 2012.

Hornecker, Eva; Stifter, Matthias. Digital backpacking in the museum with a SmartCard. In: ACM SIGCHI NEW ZEALAND CHAPTER'S INTERNATIONAL CONFERENCE ON COMPUTER-HUMAN INTERACTION DESIGN CENTERED HCl, 7., 2006. Proceedings... New York:ACM, 2006a. p. 99-I07.

Hornecker, Eva; Stifter, Matthias. Learning from interactive museum installations about interaction design for public settings. In: AUSTRALIA CONFERENCE ON COMPUTER-HUMAN INTERACTION, I 7., 2006. Proceedings... New York:ACM, 2006b. p. I35-I42. Disponível em: <http://www.ehornecker. de/Papers/OzCHI06TMW.pdf>.Acesso em: I5 jun. 2012.

Hughes, Philip. Exhibition design. London: Laurence King Publishing, 2010.

martins, Maria Helena Pires.Apresentação. In: CURY, Marilia Xavier. Exposição: concepção, montagem e avaliação. São Paulo:Annablume, 2005.

McLean, Kathleen. Planning for people in museum exhibitions. Washington, DC:Association of Science-Technology Centers, 1993.

Oliveira, José Cláudio Alves de. O Museu e a sua arquitetura no mundo globalizado: entre informação e virtualidade. Museologia \& Interdisciplinaridade, Brasília, v. I, n. I, jan./jul. 2012.

SARTIN,Antonio Carlos de Moraes.A experiência e a experimentação no Museu da Língua Portuguesa: relatos e observações. In: BENCHETRIT, S. F;; BEZERRA, R. Z.; MAGALHÃES, A.M. (Org.). Museus e comunicação: exposições como objeto de estudo. I. ed. Rio de Janeiro: Museu Histórico Nacional, 20 I0. v. I, p. 259-272.

SCHEINER, Tereza. Comunicação, educação, exposição: novos saberes, novos sentidos. Semiosfera, v. 3, n. 4/5, 2003. Disponível em: <http://www.semiosfera. eco.ufrj.br/anteriores/semiosfera45/conteudo_rep_tscheiner.htm>. Acesso em: 13 maio 2012.

SCHEINER, Tereza. Museus e exposições em um mundo em mudanças: novos desafios, novas inspirações. Revista Museu:cultura levada a sério,Artigos de 18 de maio, 2012. Disponível em: <http://www.revistamuseu.com.br//8demaio/ artigos.asp? $\mathrm{id}=32832>$. Acesso em: 26 maio 2012.

Screven, Chan G. Présentations didactiques pour visiteurs libres. ICOM Education, n. I2-13, p. 10-20, 1993.

SWIADER, Lawrence. Using technology in the permanent exhibit of the United States Holocaust Memorial Museum: thoughts after a major evaluation. In: INTERNATIONAL WORKSHOP: RE-THINKING TECHNOLOGY IN MU- 
SEUMS:TOWARDS A NEW UNDERSTANDING OF PEOPLE'S EXPERIENCE IN MUSEUMS, 2005. Proceedings... Limerick: Interaction Design Centre, 2005. Disponível em: <http://www.idc.ul.ie/museumworkshop/Papers/Swiader.pdf>. Acesso em: 30 maio 2012.

Valinho, Patrícia Teles; Franco, Ivan. Tecnologia, interacção e cultura: novos horizontes. In: CONGRESSO DA ASSOCIAÇÃO PORTUGUESA DE CIÊNCIAS DA COMPUTAÇÃO (SOPCOM), 4., 2005. Anais... Aveiro: Comissão Editorial da Universidade de Aveiro, 2005. Disponível em: <http://www.sopcom.pt/actas/valinho-franco-tecnologia-interaccao-cultura-novos-horizontes. pdf $>$. Acesso em: 30 maio 2012.

vom Lehn, Dirk; Heath, Christian; Hindmarsh, Jon. Rethinking interactivity: design for participation in museums and galleries. Cambridge: Design Office Group, 2010. (Work, interaction \& technology research group). Disponível em: <http://www.eng.cam.ac.uk/DesignOffice/cmt/resources/pdf/vom_lehnetAl.pdf $>$. Acesso em: I 0 jun. 2012.

Wagensberg, Jorge. Princípios fundamentales de la museología científica moderna. Alambique: didáctica de las ciencias experimentales, Barcelona, n. 26, p. I5-19, 2000.

Wagensberg, Jorge. The "total" museum, a tool for social change. História, Ciências, Saúde-Manguinhos, Rio de Janeiro, v. I2, suplemento, p. 309-32I, 2005. 